the

省 abdus salam

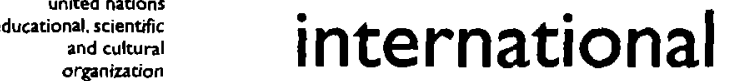

(\$) centre for theoretical physics

S. Slavov

I. Paskaleva

M. Kouteva

F. Vaccari

and

G.F. Panza

\section{XA0203560}

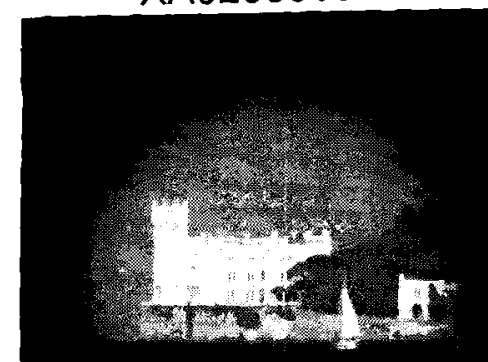

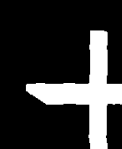

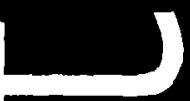

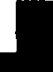

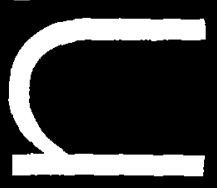

-
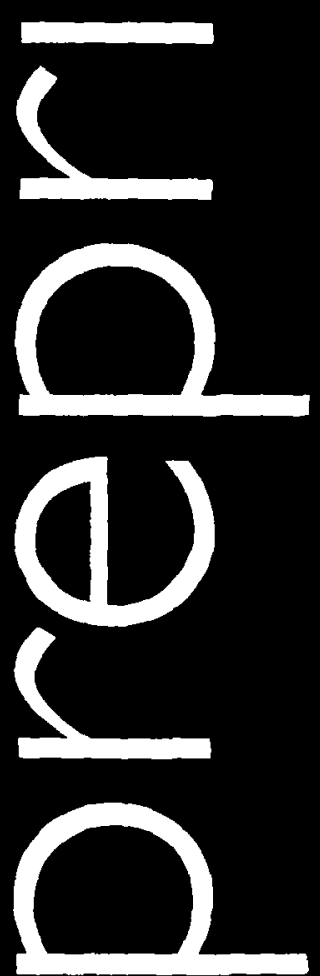
United Nations Educational Scientific and Cultural Organization and International Atomic Energy Agency

THE ABDUS SALAM INTERNATIONAL CENTRE FOR THEORETICAL PHYSICS

\title{
DETERMINISTIC EARTHQUAKE SCENARIOS FOR THE CITY OF SOFIA
}

\author{
S. Slavov \\ Department of Physics, University of Sofia, Bulgaria, \\ I. Paskaleva \\ Central Laboratory of Seismic Mechanics and Earthquake Engineering, \\ Bulgarian Academy of Sciences, Sofia, Bulgaria, \\ M. Kouteva \\ Central Laboratory of Seismic Mechanics and Earthquake Engineering, \\ Bulgarian Academy of Sciences, Sofia, Bulgaria \\ and \\ Department of Earth Sciences, University of Trieste, Trieste, Italy, \\ F. Vaccari \\ INGV, Osservatorio Vesuviano, Naples, Italy \\ and \\ Department of Earth Sciences, University of Trieste, Trieste, Italy \\ and \\ G.F. Panza \\ Department of Earth Sciences, University of Trieste, Trieste, Italy \\ and
}

The Abdus Salam International Centre for Theoretical Physics, SAND Group, Trieste, Italy.

MIRAMARE - TRIESTE

August 2002 


\begin{abstract}
The city of Sofia is exposed to a high seismic risk. Macroseismic intensities in the range of VIII - X (MSK) can be expected in the city. The earthquakes, that can influence the hazard at Sofia, originate either beneath the city or are caused by seismic sources located within a radius of $40 \mathrm{~km}$. The city of Sofia is also prone to the remote Vrancea seismic zone in Romania, and particularly vulnerable are the long - period elements of the built environment. The high seismic risk and the lack of instrumental recordings of the regional seismicity makes the use of appropriate credible earthquake scenarios and ground motion modelling approaches for defining the seismic input for the city of Sofia necessary. Complete synthetic seismic signals, due to several earthquake scenarios, were computed along chosen geological profiles crossing the city, applying a hybrid technique, based on the modal summation technique and finite differences. The modelling takes into account simultaneously the geotechnical properties of the site, the position and geometry of the seismic source and the mechanical properties of the propagation medium. Acceleration, velocity and displacement time histories and related quantities of earthquake engineering interest (e.g. response spectra, ground motion amplification along the profiles) have been supplied. The approach applied in this study allows us to obtain the definition of the seismic input at low cost exploiting large quantities of existing data (e.g. geotechnical, geological, seismological). It may be efficiently used to estimate the ground motion for the purposes of microzonation, urban planning, retrofitting or insurance of the built environment, etc.
\end{abstract}




\section{Introduction}

The city of Sofia is the main administrative centre in Bulgaria, with the densest population. Large industrial zones are located in its vicinity. If a strong earthquake should occur in Sofia area it could produce disastrous damages in a large region, followed by numerous heavy consequences for the whole country (communications, lifelines). Therefore the purpose of our study is to:

(1) contribute to the earthquake hazard assessment of Sofia, providing earthquake scenarios with respect to specific earthquakes that can affect the city, as suggested by the geological outline, the regional earthquake hazard and the seismicity record at Sofia;

(2) supply synthetic seismic signals computed using source and structural models available in the literature and to validate these theoretical results on the base of the available reports on earthquake damages;

(3) provide site response estimates at Sofia due to the chosen earthquake scenarios.

In general there are two main classes of methods used to generate synthetic ground motion: numerical and analytical methods. In this study, the synthetic ground motion was generated applying a hybrid approach [Fäh et al., 1993; 1994a, b]. It combines the modal summation technique [Panza, 1985; Panza and Suhadolc, 1987; Panza et al., 2000], used to describe the seismic wave propagation in the anelastic bedrock structure with the finite difference method [Virieux, 1984; 1986; Levander, 1988] used for the computation of wave propagation in the anelastic, laterally inhomogeneous sedimentary media. The computations were performed separately for the SH and P-SV waves. This hybrid procedure was already successfully proved for several major cities: Mexico [Fäh et al., 1994b], Rome and Naples, Italy [Fah et al., 1994a; Vaccari et al., 1995], Bucharest [Panza et al., 2002], Thessaloniki [Triantafyllidis et al., 1998], Beijing [Sun et al., 1998], Naples [Nunziata et al., 2000], Zagreb [Lokmer et al., 2001].

\section{Geological outline}

Sofia valley is situated in the northernmost part of the Central-Balkan neotectonic region. It coircides with the Sofia graben, a structure situated in the downlift regions of the western part of the Sredna Gora tectonic zone. In the South the graben is limited by a fault belt, which extends along the north edge of Vitosha and Lozen mountains and in the North by Negushevo fault zone [Christoskov et al., 1989; Jaranoff, 1960]. Recent neotectonic studies [Tzankov and Nikolov, 1996] consider that the graben had been developed under the leading part of the listric faulting along the two sides of the corresponding segment of the first-rate neotectonic Maritza protofracture. This protofracture passes through the axial part of the Sofia field and marks the initial zone of the extension opening of the fault basin. The seismicity of the zone is related mainly to the marginal neotectonic faults of Sofia graben [Solakov et al., 2001]. There are two main fault structures with Southeast - Northwest direction present in the region. Other cross faults as well as a number of disjunctive disturbances, e.g. the Lozen terrace, the central Sofia terrace, Slatina uplift, give a contribution to the regional seismicity.

The Sofia Kettle extends from East to West along a length of $75 \mathrm{~km}$ and a width of up to 26 $\mathrm{km}$ in its western part. The average altitude at Sofia Kettle is about $550 \mathrm{~m}$. The Kettle is relatively flat with a relief gradually raising towards the surrounding mountains. The city of Sofia is situated in the central part of the Kettle, near the foot of the Vitosha and Ljulin mountains. The Quaternary cover, building up the uppermost part of the Sofia Kettle, is from 3 $\mathrm{m}$ to $100 \mathrm{~m}$ thick and more. It is covered by Pliocene and Quaternary sediments with a thickness from $200 \mathrm{~m}$ to $700 \mathrm{~m}$, in some places up to $1200 \mathrm{~m}$. The Quaternary sediments, rather different in their composition and properties, are widespread and lie over older rock and soils. The 
permeability of these sediments predetermines the shallow water table in the region and the possibility for suffusion or liquefaction of the fine water-saturated sands. Neogene sediments with various grain size distributions and high content of silt fraction $(42-82 \%)$, take part up to depth of $25-30 \mathrm{~m}$ below the surface [Frangov, 1995; Ivanov, 1997; Ivanov et al., 1998]. The "cultural" layer is composed of old structures, technogenic soils, industrial and household waste. The first layer of old structure remnants is the thickest one in the central part of the town (up to $10 \mathrm{~m}$ ). The distribution of the technogenic soils, composed of reworked rocks and soils and industrial waste, is around the opened pits, the big city residential buildings and the power stations. Recently a detailed geological map of the surface soil conditions at Sofia (23.30E, $42.60 \mathrm{~N}-23.50 \mathrm{E}, 42.80 \mathrm{~N}$ ) has been constructed [Paskaleva and Kouteva, 2001]. It covers a grid $1 \times 1 \mathrm{~km}$, following a four - degree scale, where soils are distinguished as rocks (soil parameter $s=3)$, intermediate soils $(s=1,2)$ and weak soils $(s=0)$. Among all these soil types present at Sofia, the intermediate weak soils take a predominant part in the area of interest.

\section{Local seismicity}

Strong earthquakes with magnitude, M, up to 7 did shake Sofia in the past centuries [Bonchev et al., 1982; Shebalin et al., 1999, Solakov et al., 2001]. During the last two centuries three destructive earthquakes occurred: in $1818, \mathrm{M}_{s} \sim 6.0$ ), in $1858, \mathrm{M}_{\mathrm{s}} \sim 6.5$ (near the town of Sofia, macroseismic intensity $I=I X-X, M S K-64$ ) and in 1905, $M_{s} \sim 6.5$ (in the western marginal part of the Sofia Kettle). In the same period several weaker events with I = VI - VII (MSK - 64) have also been reported. In $1907(M=4.6), 1909(M=4.6)$ and $1910(M=4.8)$ earthquakes with I up to V - VI (MSK) were felt in Sofia. On October 18, 1917, a strong earthquake $(M=5.3)$ with epicenter in the vicinity of Sofia occurred and the maximum observed macroseismic intensity has been I = VII - VIII (MSK), [Kirov, 1952; Petkov and Christoskov, 1965; Christoskov, 1992]. In the recently compiled earthquake catalogue [Shebalin et al., 1999], for the region of Sofia, limited by the rectangle $42.25 \mathrm{~N}, 22.75 \mathrm{E}-43.25 \mathrm{~N}, 24.00$ E, 79 events within the magnitude interval $M=4-7$ have been reported for the time period 1687 - 1990. In fact, since 1900 four earthquakes with magnitude 5 and higher occurred in the valley: 1904 , Apr. $11, M=5.2,1912$, Sept. $16, M=5.3,1928$, Apr. 18, $M=5.0$, and 1934, June $7, \mathbf{M}=5.3$. No strong events have been reported, but the tectonic processes generating the earthquakes are obviously still active [Paskaleva et al., 2002]. During the period $1977-2000$, 147 events occurred in the Sofia seismic zone, the strongest one (1980, Sept. 03) had magnitude $\mathrm{M}=4.3$ [NEIC]. In 1983 epicentral macroseismic intensity $\mathrm{Io} \sim \mathrm{V}$ and $\mathrm{I}=\mathrm{III}-\mathrm{V}$ were reported for Sofia and vicinity due to the earthquake of Dec. $22, M=3.6$, which stroke just beneath the city [Glavcheva, 1993].

An epicentres map of all reported seismic events with magnitude $M=4.0-7.0$ is shown in fig. 1 [Matova, 2001]. The weak earthquake epicentres are located along the faults as well as in the horsts to the north, east and south of the Sofia graben. The strong and moderate earthquake epicentres are concentrated along the faults, and also in the fault crossing joints, mainly in the central and the southern parts of the Sofia graben. The earthquakes with focal depths of $11-30$ $\mathrm{km}$ are concentrated near the Vitosha fault and in the vicinity of its crossings with the Chepintsi and the Vladaya faults (fig. 1).

\section{Earthquake Hazard Estimates}

Several studies on the seismic hazard in Bulgaria [Bonchev et al., 1982; Orozova Stanishkova et al. 1994, 1996] and particularly for Sofia [Petkov and Christoskov, 1965; Christoskov et al., 1989; Stanishkova and Slejko, 1991; Ranguelov and Toteva, 1996, 1998; 
Solakov et al., 2001], based on different approaches, have shown the high seismic hazard at Sofia and surrounding area. Maximum macroseismic intensity at Sofia, I = IX (MSK), already observed in 1858 [Bonchev et al., 1982], can be expected to occur within a period of 150 years [Christoskov et al., 1989]. The recently constructed seismic hazard maps of the Circum Panonian Region [Panza and Vaccari, 2000] show that Sofia could suffer macroseismic intensity up to VIII - X (MSK - 76) [Medvedev, 1977]. The first seismic microzonation map for Sofia was constructed in 1964 in terms of macroseismic intensity [Petkov and Christoskov, 1965]. In this map three zones can be distinguished: zone " $A$ ", which covers the south - eastern central part of the town with maximum expected intensity (MSK) I = IX and some small "spots" out of this part; zone "B" with $I=I-1$ that covers mainly the northern part of the centre of the town, and zone " $C$ " with intensity $I=I-1$ up to $I-2$, that covers most of the city area, at that time. This seismic microzonation map has been extended to a larger area of the city. The macroseismic intensity at Sofia varies within 2 degrees (MSK). The intensity variation along the considered profiles is used to control the validity of the obtained theoretical results (fig.4, fig.5). If coseismic effects are considered (e.g. land-sliding, liquefaction) the intensity still varies within the same interval $\Delta I=2$. In this case its distribution within the investigated territory changes visibly, particularly in the south - western part of the region, but the maximum intensity remains at the southern part of the city centre.

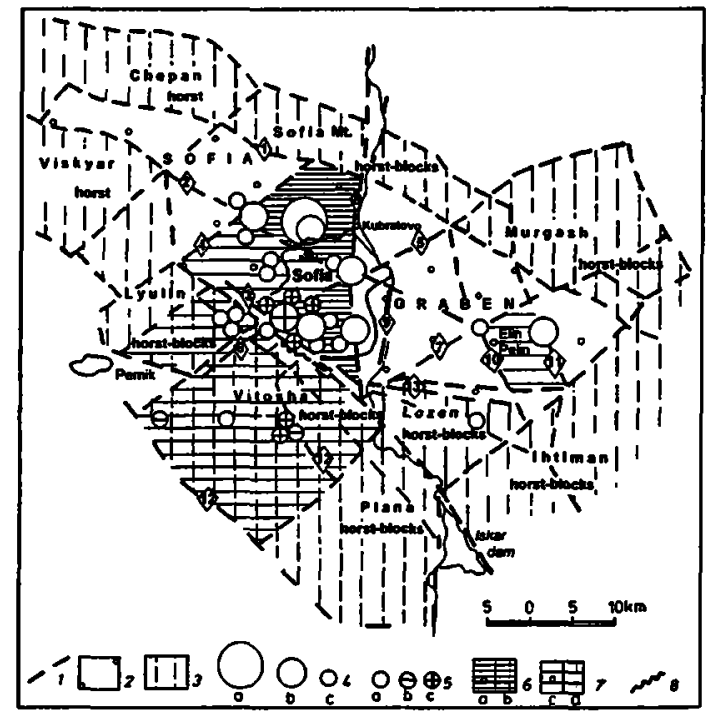

Figure 1.

Seismic events with magninude $M=4.00-7.00$ in the blocks of the Sofia graben and the adjacent horsts. 1 - faults: a - block boundary, $b$ - sector of the Vitosha fault zone activated during the 1858 Sofia earthquake $(M=6.5-7.0) ; 2$ - the block of the Sofia graben. 3 - the block of the adjacent horsts, 4 - epicentres of earthquakes with magnitude: $a-M=6.0-7.0 ; b-M=5.0-5.9$, c - M=4.0-4.9; 5 - depths of earthquake hypocentres: a - up to $10 \mathrm{~km}, \mathrm{~b}-11-20 \mathrm{~km}, \mathrm{c}-21-30 \mathrm{~km} ; 6$ - blocks of considerable seismic mobility: $a$ - of the graben, $b$ - of the horsts; 7 - blocks of moderate seismic mobility: $a$ - of the graben, $b$ - of the horsts: 8 - seismic active sector of Vitosha fault during the Sofia earthquake in 1858.

Several papers have been published on the seismic hazard in Bulgaria [e.g. Bonchev et al., 1982; Orozova-Stanishkova and Slejko, 1994]. Different authors consider different seismic zones that can influence the seismic hazard at Sofia [e.g. Paskaleva and Kouteva, 2001; Solakov et al., 2001]. Kresna, Plovdiv, Negotinska Krayna and Gorna Orjahovitza are considered as the main seismic zones in Bulgaria that can influence the seismic hazard of Sofia. Sofia is also prone to the remote Vrancea seismic zone (Romania), the long-period elements of the built environment being particularly vulnerable to these events. The available data are rather limited 
and the statistical determination of the coefficients of the Frequency - Magnitude Relationships (FMR) for these zones is affected by large uncertainties [Molchan et al., 1997]. Some preliminary computations were carried out applying a maximum likelihood based procedure [Molchan et al., 1997]. Two schematic tectonic models [Todorovska et al., 1995; Paskaleva and Kouteva, 2001] were considered with respect to the Earthquake Catalogue for East and Southeast Europe, [Shebalin et al., 1999] for the Bulgarian territory and the Romanian earthquake catalogue for Vrancea zone in Romania, ROMPLUS [www.infp.infp.ro]. The preliminary estimates of these coefficients, which are given in Table 1, show quite large confidence intervals for the $b$ - values.

The probabilistic seismic hazard analysis (PSHA) for the Sofia area, carried out by Solakov et al. [2001] provides a sensitivity analysis of the PGA, keeping the same seismic source model and the same seismicity characteristics, and varying the standard deviations in the PGA attenuation mode. A difference up to $200 \%$ in the PGA value for 1000 years period was obtained and this result has been related to the fact, that regional, but not local attenuation functions were used. A doubt comes from the fact, that in general the regional data sets are statistically not significant to represent the very different seismotectonic styles that are not mixable, and usually attenuation functions are derived with the assumption of the same propagation model for all the events considered [Decanini et al., 2001]. In this study an attempt to avoid such uncertainties, when particularly accounting for site response in the seismic hazard analyses, is performed. In our computations a deterministic procedure for ground motion modelling, capable of synthesising the seismic ground motion from basic understanding of fault mechanism and seismic wave propagation has been applied [Fäh et al., 1993; 1994a, b].

\section{Table 1}

Estimates of the $b$ coefficient of the FMR

\begin{tabular}{lll}
\hline \multicolumn{1}{c}{ Seismic zone } & \multicolumn{1}{c}{$\mathrm{b}$} & $\mathrm{b}$ \\
& tectonic model 1 & tectonic model 2 \\
\hline Sofia & $0.50+/-0.30$ & $0.55+/-0.33$ \\
\hline Negotinska Krayna & & $1.01+/-0.50$ \\
\hline Kresna & $0.69+/-0.08$ & $0.72+/-0.08$ \\
\hline Plovdiv & $0.73+/-0.08$ & $0.76+/-0.10$ \\
\hline Gorna Orjahovitza & $0.80+/-0.20$ & $0.76+/-0.23$ \\
\hline Vrancea & $0.65+/-0.15$ & $0.70+/-0.15$ \\
\hline
\end{tabular}

\section{Parameterization of the earthquake scenarios and the models adopted}

The seismicity of Sofia region involves the upper $20-30 \mathrm{~km}$ of the lithosphere. Maximum macroseismic intensity I = VIII - IX can be expected at Sofia [Glavcheva, 1990], if earthquake with maximum magnitude Mmax = 7 [Bonchev et al., 1982] occurs at depth of about $20 \mathrm{~km}$. Maximum macroseismic intensity IX (and higher) can be provoked by event with Mmax $=6.5$ and focal depth around $7 \mathrm{~km}$. In the computations carried out in this study, on the basis of the earthquake history at Sofia and on the available seismic hazard assessments provided in the literature, three shallow earthquake scenarios (Table 2) were considered. They correspond to seismic sources, located at different distances and azimuths (up to $30 \mathrm{~km}$ far from Sofia) [Slavov, 2000]. Some preliminary computations were carried out with respect to a local seismic source that can strike just beneath the city. The earthquakes epicentres correspond to real seismic events, which hit Sofia in the past: March 9, 1980; December 22, 1983; December 14, 1995 and April 20, 1996. The complete scenarios are constructed considering the conservative combinations of information available in the literature [e.g. NEIC, Shanov et al., 1992; Glavcheva et al., 1996]. 
Table 2

Earthquake scenarios studied by the numerical experiments

\begin{tabular}{|c|c|c|c|c|c|c|c|c|}
\hline \multirow{3}{*}{$\begin{array}{c}\text { Profile } \\
\text { identification } \\
\text { as shown in } \\
\text { fig. } 3\end{array}$} & \multirow{2}{*}{\multicolumn{3}{|c|}{$\begin{array}{l}\text { Earthquake date, } \\
\text { location, latitude (La) } \\
\text { Longitude (Lo) } \\
\text { magnitude (M) }\end{array}$}} & \multicolumn{5}{|c|}{$\begin{array}{c}\text { Seismic source moment tensor considered in the } \\
\text { computations }\end{array}$} \\
\hline & & & & Strike & Dip & Rake & & $\begin{array}{l}\text { Epicentral } \\
\text { distance to }\end{array}$ \\
\hline & $\mathrm{La}[\mathrm{J}$ & Lo[] & $\mathbf{M}$ & {$[0]$} & {[} & {$[1]$} & [km] & {$[\mathrm{km}]$} \\
\hline \multirow{2}{*}{ AB } & 42.95 & 23.36 & 4.4 & 135 & 43 & 111 & 10 & 25.0 \\
\hline & 42.76 & 23.39 & 3.6 & \multicolumn{5}{|c|}{$\begin{array}{l}\text { A Ricker impulse introduced at } 2 \mathrm{~km} \text { beneath } \\
\text { the city }\end{array}$} \\
\hline$C D$ & 42.54 & 23.52 & 3.3 & 21 & 44 & 309 & 2 & 8.6 \\
\hline EF & 42.79 & 23.49 & 6.5 & 340 & 77.6 & 285 & 8 & 15.0 \\
\hline
\end{tabular}

A generalised scheme of the model adopted for the numerical experiments is shown in fig. 2. The seismic waves propagation path consists of the travelled path between the source and the target site (the "bedrock structure") and the target local cross sections. The data used to build up the local structural models, down to $1000 \mathrm{~m}$ below the surface, are obtained from a large set of boreholes and geological cross sections [Petrov and Iliev, 1970; Kamenov and Kojumdgieva, 1983; Frangov, 1995; Ivanov, 1997; Ivanov et al., 1998]. The lower part of the local model, describing the structure below this $1 \mathrm{~km}$, coincides with the bedrock velocity model, available in the literature and assumed to be the same for the Sofia Kettle [Stanishkova and Slejko, 1991]. A summary of the geophysical properties of the geological strata under the city of Sofia considered in this study is shown in Table 3. The models' grids, used in the computations, are summarised in Table 4. This study deals with the two-dimensional problem of wave propagation and ground motion modelling. Considering the regional topography of the studied area, it is advisable to perform some investigations, implementing a three-dimensional model as well. This can be done as soon as significant records will be available and that will allow the as'essment of possible 3-D effects.

Table 3

\begin{tabular}{|c|c|c|c|c|c|}
\hline \multirow[t]{2}{*}{ Layer } & \multirow{2}{*}{$\begin{array}{l}\text { Density } \\
\rho\left[\mathrm{kg} / \mathrm{m}^{3}\right]\end{array}$} & \multicolumn{2}{|c|}{$\begin{array}{l}\text { Seismic wave propagation } \\
\text { velocities }\end{array}$} & \multicolumn{2}{|c|}{ Attenuation factor, $\mathbf{Q}$} \\
\hline & & $\mathrm{Vp}[\mathrm{m} / \mathrm{s}]$ & Vs $[\mathrm{m} / \mathrm{s}]$ & Qp & Qs \\
\hline Soil Layer & 1800 & 310 & 180 & 40 & 15 \\
\hline Quaternary cover & 1970 & 950 & 550 & 50 & 20 \\
\hline $\begin{array}{l}\text { Tertiary } \\
\text { sediments }\end{array}$ & 1920 & 1400 & 800 & 75 & 30 \\
\hline Senonian marls & 2000 & 1900 & 1100 & 100 & 40 \\
\hline $\begin{array}{l}\text { Triassic } \\
\text { limestones }\end{array}$ & 2020 & 2100 & 1200 & 120 & 50 \\
\hline $\begin{array}{l}\text { Senonian } \\
\text { andesites }\end{array}$ & 2540 & 3600 & 2100 & 200 & 80 \\
\hline
\end{tabular}


Table 4

\begin{tabular}{crrrrr}
\multicolumn{3}{c}{ Mesh and model size considered in the } & $F D$ computations \\
\hline \multirow{2}{*}{ Profile } & \multicolumn{2}{c}{ Mesh size } & \multicolumn{3}{c}{ Model size } \\
\cline { 2 - 6 } & $\begin{array}{c}\mathrm{X}, \\
\text { grid points }\end{array}$ & $\begin{array}{c}\mathrm{Z}, \\
\text { grid points }\end{array}$ & $\begin{array}{c}\mathrm{X}, \\
\mathrm{km}\end{array}$ & $\begin{array}{c}\mathrm{Z}, \\
\mathrm{km}\end{array}$ \\
\hline $\mathrm{AB}$ & 2082 & 577 & 10.41 & 19.80 \\
\hline $\mathrm{CD}$ & 2939 & 310 & 11.76 & 3.95 \\
\hline $\mathrm{EF}$ & 2978 & 474 & 11.91 & 10.00 \\
\hline
\end{tabular}

\section{Numerical experiments and discussion of the results}

Complete synthetic seismic signals have been generated for all sites of interest along the profiles investigated, fig. 3 ( $\sim 100$ sites per profiles), following the earthquake scenarios given in Table 2. Two groups of experiments have been performed: (A) ground motion modelling, applying an algorithm based on the modal summation method [Panza, 1985; Panza and Suhadolc, 1987], 1D, and (B) modelling, making use of the hybrid technique [Fäh et al. 1993; $1994 \mathrm{a}, \mathrm{b}], 2 \mathrm{D}$. The distant seismic sources were considered as buried double-couple point sources. The local seismic source was modelled by introducing a single Ricker impulse at the bottom of the model.

The chosen frequency interval (up to $5 \mathrm{~Hz}$ ) covers practically the whole range of elements of the built environment present at Sofia. Seismic waves along the profiles investigated (fig.3, Table 2) are computed and acceleration, velocity and displacement time histories are obtained for all ground motion components, transverse (TRA), radial (RAD) and vertical (VER). Different quantities ofearthquake engineering interest, like peak ground accelerations (PGA), peak ground velocities (PGV), peak ground displacements (PGD), response spectra amplitudes (SA) and PGA / PGV ratios, are derived from the computed seismic signals. The site re sponse along the investigated profiles is defined as Response Spectra Ratio (RSR). These RSR a re the ratios between the amplitudes of the response spectra, for 5\% damping (SA), computed taking into account the local heterogeneous media (SA2), and the corresponding values obta ned considering only the bedrock structure (SA1), RSR = SA2 / SA1. The distributions of F SR versus frequency and epicentral distance for all studied scenarios have been mapped.

Comparisons between the seismic signals, simulated by the modal summation method and those, obtained applying the hybrid technique for the simple bedrock layered structural model have been carried out. These tests are always necessary when the hybrid approach is applied in a new region. The differences between both the modal summation method and the hybrid technique are negligible (less than 3 - $5 \%$ ). It means that the control of the accuracy of the FD part of the computations, depending upon the efficiency of the absorbing boundaries, the correct discretization of the structural model, the presence of all phases in the seismograms and the treatment of anelasticity, has been successfully achieved.

To validate the theoretical computations, the observed macroseismic information was used. No instrumental data is available for the considered events, since the digital seismological station (VTS - Sofia) started to operate in May 1996. The macroseismic maps for the earthquakes in 1907, 1909, 1910, 1917, 1941, 1947 and 1952 [Petkov and Christoskov, 1965; Glavcheva, 1990; Christoskov et al., 1989] are too general with respect to the microzonation purposes and no information is available on the fault plane solution of the mapped earthquakes. The few published maps of seismic microzonation for Sofia [Petkov and Christoskov, 1964; Solakov, 2001] show maximum variations within two degrees of macroseismic intensity. 
Macroseismic intensity variation $\Delta \mathrm{I}=2$ is reported also for the quake of December 22 [Glavcheva, 1990], that has been considered for the computations of the ground motion along the $\mathrm{AB}$ profile. The existing relation between PGA and the macroseismic intensity, I [Medvedev 1977], and between PGA / PGV and I [Seed and Idriss, 1982] have been used to provide theoretical estimates of the macroseismic intensity of each site. The theoretically estimated macroseismic intensity varies within 2 degrees in the investigated region, which is in agreement with the available observation. The synthetic signals obtained considering an earthquake scenario with magnitude $M=6.5$ and focal depth $H=8 \mathrm{~km}$ show $200 \mathrm{~cm} / \mathrm{s}^{2}<P G A<400 \mathrm{~cm} / \mathrm{s}^{2}$, $\mathrm{I}=$ VIII - IX [Medvedev 1977]. This result is consistent with the parameterisation of the isoseimals from Bulgarian earthquakes [Glavcheva, 1990].

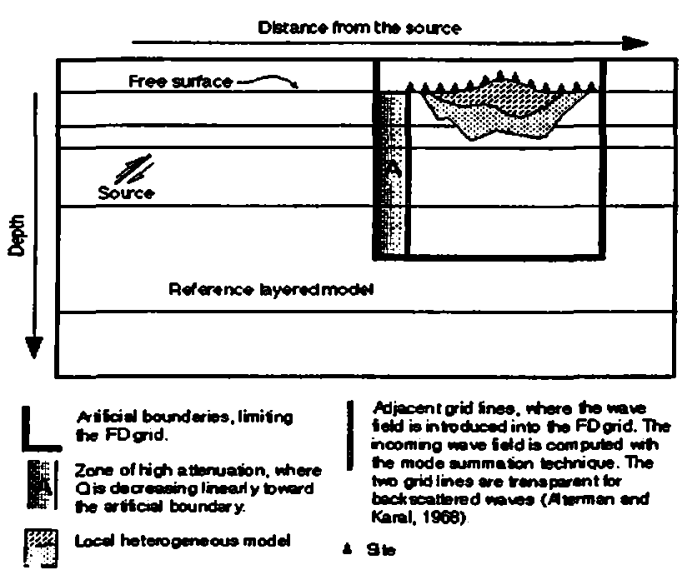

Figure 2

A generalised scheme of the model adopted for the numerical experiments.

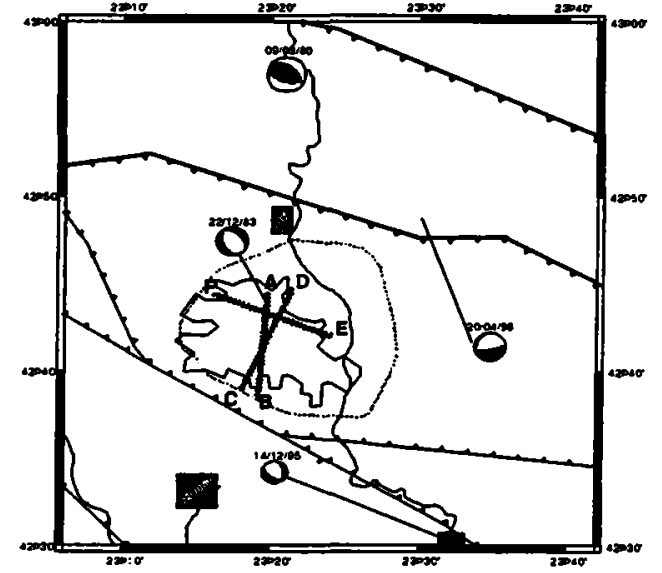

Figure 3

A generalised tectonic scheme of Sofia region, investigated profiles ( $A B, C D$ and $E F$ ), location and focal mechanisms of the considered earthquakes.

The maximum SA2 (5\% damping) values were normalised to the corresponding SA1 v. Jues for each site along the profiles investigated. The results for all components TRA, RAD and VER are shown in figs. 4.1 - 4.3. Along profile AB, fig. 4.1, the theoretical curves for TRA, ZAD and VER justify the one-degree intensity increment, but they fail to explain larger intensity increments. Regarding the scenario, dealing with earthquakes beneath the city, the TRA - SA ratio variation matches the reference intensity graph within epicentral distances 25 $26 \mathrm{~km}, 28-30 \mathrm{~km}$ and $31-33 \mathrm{~km}$. Most impressive are the results we obtained along profile CD (fig. 4.2). The peaks in the SA(2D)/SA(1D) for all components TRA, RAD and VER follow the lateral variation of the structural model. The variation of SA(2D)/SA(1D) explains well local intensity increments as large as 3 , and in general are in agreement with the variation of $I$ along the profile. For both profiles $\mathrm{AB}$ and $\mathrm{CD}$ the VER component does not seem to be correlated with the intensity variation. The possible correlation of the computed amplification of the VER component to the observed damage has already been reported [e.g. Lokmer et al., 2001; Panza et al., 2002].

Along the EF profile (fig. 4.3) the RSR for the horizontal components varies within 2 and 4, in agreement with the reported one-degree local intensity increment. The comparison between the intensity, theoretically estimated on the base of the PGA(2D)/PGA(1D) or PGV/PGA ratios and the reported intensity, leads to similar conclusions. The observed mismatch between the synthetic signals and the reported intensity is not surprising. It may warrant refinement and 
renovation of the seismic microzonation intensity maps, however it can be due to inadequacies in the assumed parameters describing the source and the medium.

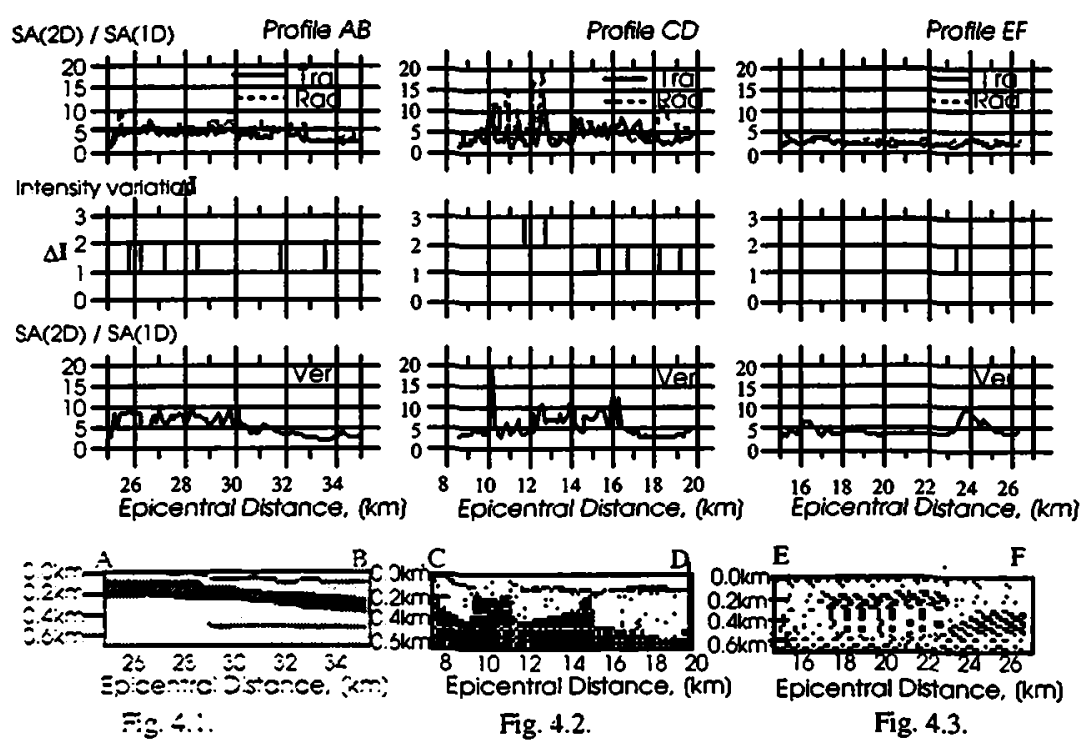

Figure 4

Spectral ratio Sa(2D)/SA(1D) for $5 \%$ damping, along the profile investigated (as shown in fig. 3). Comparison with the macroseismic intensity I [MSK] variation graph along the same profiles (a fragment of map of seismic microzonation of Sofia). Transverse (TRA - solid line), radial (RAD - dashed line) and Vertical (Ver) components are shown). Fig. 4.1:Profile AB; Fig. 4.2: profile CD: Fig. 4.2: Profile EF.

A successful test for the numerical modelling of the ground motions at Sofia comes from most of the PGV/PGA ratios. The computed ratios are in agreement with the values suggested by Seed and Idriss [1982] and Decanini (p. com. 1998) for intermediate soils (Vs $<0.3 \mathrm{~km} / \mathrm{s}$ ) and rocks and deep stiff soils $(0.6 \mathrm{~km}>\mathrm{Vs}>0.3 \mathrm{~km} / \mathrm{s})$, figs. $5.1-5.3$.

Site amplification is estimated in terms of RSR distributions versus frequency and epicentral distance (figs. 6.1 - 6.3). In fig. 6.1 the site amplification along the $A B$ pro.ile exposed to a distant earthquake is shown. One can see that the TRA component is amplified up to $4.6(1.5-2.0 \mathrm{~Hz})$, the RAD amplification reaches $3.6(1.0-1.75 \mathrm{~Hz})$ and the VER RSR got; up to 7.5 within the frequency interval $1.25-3.00 \mathrm{~Hz}$. If an earthquake strikes just beneath the profile $\mathrm{AB}$ (Table 3) then the ground motion at the site can be amplified up to $10-11$ times within the frequency interval $1.25-2 \mathrm{~Hz}$ (not shown in the figures). Along the $\mathrm{CD}$ profile (fig. 6.2 ), the highest amplification is observed for the RAD component compared to the other two components. The maximum amplifications for all ground motion components (TRA, RAD and VER) are observed at frequencies higher than $3.5 \mathrm{~Hz}$. For the RAD RSR reaches $7-8.5$ (at 2.5 $-5 \mathrm{~Hz})$, for the VER RSR is up to $3.5-5.0(3.5-5.0 \mathrm{~Hz})$ and the for the TRA, the largest RSR is about $6(3.5-4.5 \mathrm{~Hz})$. The amplification along the profile EF is shown in fig. 6.3. TRA shows rather consistent amplification (less than 3) within the whole frequency interval considered, RAD has its maximum amplification $(2.5-3.0)$ at $3.5-4.5 \mathrm{~Hz}$ and VER is amplified up to $3.5-4.0$ at frequencies $0.5 \mathrm{~Hz}$ and $1.3-1.8 \mathrm{~Hz}$. For all scenarios the maximum amplifications along the profiles correspond to the weak or intermediate soil conditions as shown in the map of engineering geological conditions at Sofia [Paskaleva and Kouteva, 2001]. 


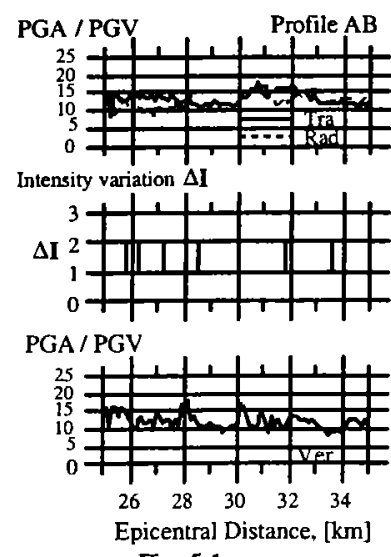

Fig. 5.1.
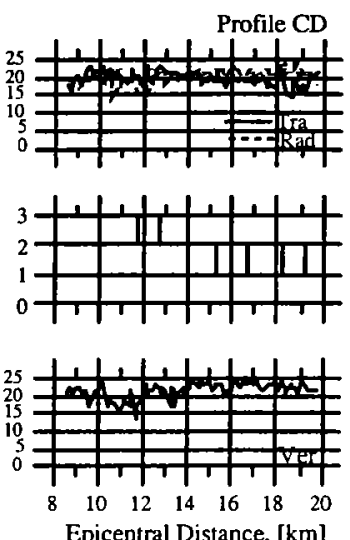

Fig. 5.2
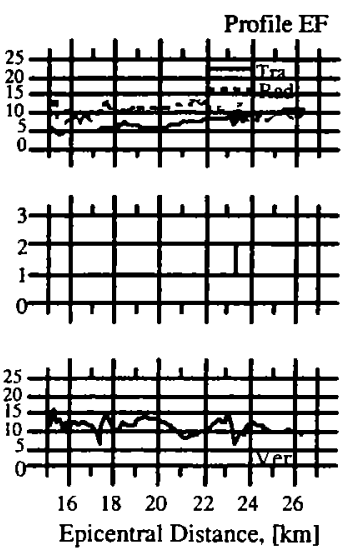

Fig. 5.3.

Figure 5

Scheme of the ratio of the peak ground velocity PGV to the peak ground acceleration PGA along the investigated profiles (as shown in fig. 3), related to the macroseismic intensity I [MSK] variation along the same profiles (a fragment of map of seismic microzonation of Sofia). Transverse (TRA - solid line), radial (RAD - dashed line) and Vertical (Ver) components are shown). Fig. 5.1:Profile AB; Fig. 5.2: profile CD; Fig. 5.2: Profile EF.

In all scenarios the presence of thick sediments leads to an increase of the ground motion amplitudes and of the amplification, due to multiple reflections. The maximum PGA values correspond to both the thickest sediments and the thickest parts of the surface low velocity layer. A comparative study of the spectral amplification of the different ground motion components show that TRA, RAD and VER give a significant contribution to the seismic input, where the RAD component exerts the biggest influence on the site amplification, reaching values up to 7 - 8 whereas, for TRA and VER components, the maximum amplification is up to 5 - 6. This result differs from the widely accepted idea, that the transverse component has a predominant role in the seismic input definition.

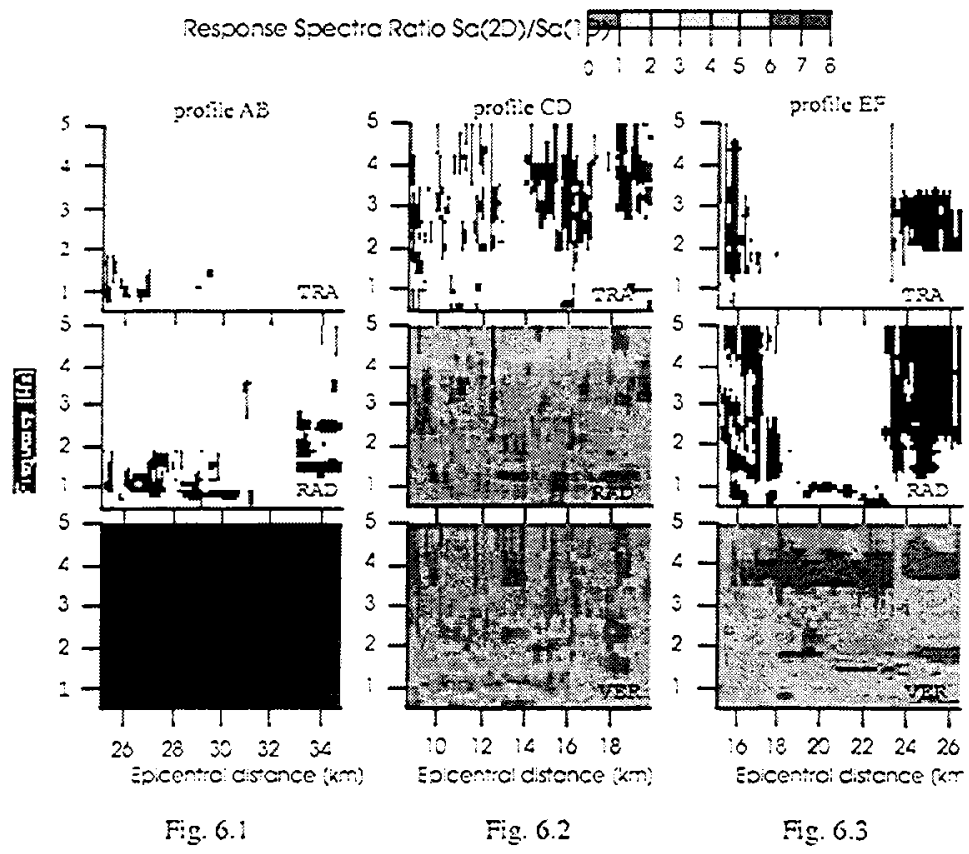

Figure 6

Site amplification defined as Response spectra ratio, RSR, mapped versus frequency and epicentral distance along the profiles investigated (as shown in fig. 3). Transverse (TRA), radial (RAD) and vertical (VER) components are shown. 
Four earthquake scenarios were chosen and complete synthetic seismic signals were generated along three geological profiles crossing the city of Sofia. A hybrid procedure that accounts simultaneously, into the ground motion estimate, the seismic source moment tensor and the mechanical characteristics of the propagating media was used. The results obtained through the theoretical modelling have been successfully compared with the macroseismic field information available.

The approach used to model the ground motion at Sofia has been capable to provide realistic acceleration, velocity, and displacement time histories and related quantities of earthquake engineering interest. The most important result concerns the site response behaviour. The comparative study of the spectral amplification of the different ground motion components shows that TRA, RAD and VER give a significant contribution to the seismic input. RAD exerts the biggest influence on the site amplification - this fact differs from the widely accepted idea, that the transverse component has a predominant role in the seismic input definition. The obtained results can be used for different engineering purposes, urban planning, retrofitting of the built environment, insurance industry, earthquake preparedness, earthquake risk reduction and earthquake risk management.

\section{Acknowledgements}

This research is a contribution to the UNESCO - IUGS - IGCP 414 Project "Realistic Modelling of Seismic Input for Mega cities and Large Urban Areas". It has also been supported by the NATO: SfP IVESB 972266 and 65/219.33/01/12/2000, by the Marie-Curie Training site grant EVK2-CT-2000-57002 and Scientific BG Fund NZ 10031. 


\section{REFERENCES}

Bonchev, E., Bune V., Christoskov, L., Karagyuleva, J., Kostadinov, V., Reisner, G., Rzikova, S., SHEBALIN, N., SHOLPO, V., SOKEROVA, D. (1982), A method for compilation of seismic zoning prognostic maps for the territory of Bulgaria, Geologica Balkanica 12/2,3-48.

Christoskov, L., Georgiev, TzV., Deneva, D., Babachkova, B. (1989), On the seismicity and seismic hazard of Sofia valley, Proc. Of the $4^{\text {th }}$ Int. Symposium on the Analysis of Seismicity and seismic risk, Bechyne castle, CSSR, IX, 1989, 448-454.

CHRISTOSKOV, L. (1992), l00 years seismology in Bulgaria, Bulg. Geoph. Journal, XVIIV1, 3-21.

Decanin,, L., Mollaioli, F., Panza, G.F., F. Romanelli, Vaccari, F. (2001), Probabilistic vs deterministic evaluation of seismic hazard and damage earthquake scenarios: a general problem, particularly relevant for seismic isolation, Proc. 7th International Seminar on Seismic Isolation, Passive Energy Dissipation and Active Control of Vibrations of Structures, Assisi, Italy, October 2-5, 2001.

FÄH, D., Iodice, C., SUHAdolc, P., AND PANZA, G. F. (1993), A new method for the realistic estimation of seismic ground motion in megacities: The case of Rome, Earthquake Spectra 9, 643-668.

FÄH, D., IODICE, C., SUHADOLC, P., PANZA, G.F. (1994a), Application of numerical simulations for a tentative seismic microzonation of the city of Rome. Annali di geofisica XXXVIII,5-6, 607-615.

FÄH, D., SUHADOLC, P., MUELLER, ST., PANZA, G.F. (1994b), A hybrid method for the estimation of ground motion in sedimentary basins; quantative modelling for Mexico city, BSSA 84, 383-399.

FRANGOV, G. (1995), Assessment of the conditions and factors, determining the geological hazards at the Sofia Kettle, Rep. To CGMR (in Bulgarian).

GLAvCHEVA R. (1990), Parametrization of the isoseismal from Bulgarian earthquakes, Bulg. Geoph. Jm XVI, 4, 3844 (in Bulgarian).

GlaVCHEVA R (1993), Atlas of Isoseismal Maps, Bulgaria 1981 - 1990, Geoph. Inst., BAS.

GlavcheVA, R., Georgiev, Tz., Botev, E., BABACHKova, BL., ToteVA, T. (1996), Sofia graben and the earthquake of December 14 1995, Bulgarian Geophysical Journal XXII, 3, 44-50.IvanOV, P., (1997), Assessment of the geological Conditions in the Sofia Kettle under seismic impact, Proc. International IAEG Conference, Athens, 1997, Balkema. Rotterdam, 1265-1270.

IVANJV, PL., Frangov,G., Yaneva,M., (1998), Engineering geological characteristics of Quatemary sediments in the Sofia graben, Proc. 3rd WG Meeting, 2-5.12.1998, Sofia, 33-37.

JAR.ANOFF, D., Tectonics of Bulgaria (Technika, Sofia 1960).

K :MENOV, B., and KoJumDIEVA, N. (1983), Stratigraphy of the Neogene in Sofia Basin, Paleontology,stratigraphy and lithology $18,69-85$.

F.IROV, K. (1952), A contribution to studying of the earthquakes in Sofia valley, An. Of main direction for geological and mine researches 5, 407-417 (in Bulgarian).

LEVANDER, A.R. (1988), Fourth-order Finite-difference P-SV seismograms, Geophysics 53, 1425-1436.

Lokmer, I., Herak, M., Panza, G.F., VacCaru, F. (2001), Amplification of strong-ground motion in the city of Zagreb, Croatia, estimated by computations of synthetic seismograms, ICTP Preprints, IC/2001/26.

MATOVA. M. (2001), Recent manifestations of seismotectonic activity in Sofia region and their land subsidence potential. Proc. Final Conf. of UNESCO-BAS Project on land subsidence, June 27-30, 2001, Sofia, 93-98.

Medvedev, S. V. (1977), Seismic Intensity Scale MSK - 76, Publ. Inst. Geophys. Pol. Acad. Sc. 117, 95-102.

Molchan, G., KRONROD, T., PANZA, G. F. (1997), Multi - Scale Seismicity Model for Seismic Risk, BSSA 87, 5. 1220-1229.

NEIC - National Earthquake Information Center, http://wwwneic.cr.usgs.gov/neis/epic/epic_global.html

Nunziata, C., Costa G., MarraRa, F., PANZA, G. F. (2000), Validated Estimation of Response spectra for the 1980 Irpinia Earthquake in the Eastern Area of Naples, Earthquake Spectra 16, 3, 643-661.

Orozova-StanishKova I., SLEJKo, D. (1994), Seismic hazard of Bulgaria , Natural hazards 9, 247-271.

Orozova-STANISHKova I., COSTA, G., VACCARI. F., SUHADOLC, P. (1996), Estimates of $1 \mathrm{~Hz}$ maximum accelerations in Bulgaria for seismic risk reduction purposes, Tectonophysics 258, 263-274.

PANZA, G.F. (1985), Synthetic seismograms: The Rayleigh waves model summation, Journal of Geophysics $58,125-$ 145.

Panza, G.F., Suhadolc, P. (1987). Complete strong motion synthetics, In Seismic Strong Motion Synthetics (Ed. Bolt B.A.) (Academic Press, Orlando,), pp.153-204.

PANZA, G. F., ROMANELLI, F., VACCARI F. (2000), Seismic wave propagation in laterally heterogeneous anelastic media: theory and applications to seismic zonation, In Advances in Geophysics, 43, pp.1-95.

Panza, G. F., VACCARI F. (2000), Introduction, In Seismic Hazard of the Circum-pannonian Region (Ed. Panza, G. F., Radualian, M., and Trifu, C.) (Pageoph Topical Volumes, Birkhauser Verlag) pp.5-10.

Panza, G. F., Cioflan, C. O., Kouteva, M., Paskaleva, I., Romanell, F. (2002), An innovative assessment of the seismic hazard from vrancea intermediate-depth earthquakes: Case studies in Romania and Bulgaria (submitted to the 12 E CEE, Rer. No.230). 
Paskaleva, I., KouteVa, M.,(2001a), A contribution to the seismic risk assessment of Sofia region and the town of Russe from deterministic modelling, Report on Bilateral Project "Engineering Seismic Hazard and Risk Assessment of Selected Cities in the Balkan region", CLSMEE-BAS - DST-UNIVTS, May-June 2001.

PASKALEVA, I. and KoUTEVA M. (2001), An approach for microzonation of the town of Russe in connection with recent Vrancea earthquakes and Shabla zone, Report on bilateral project Engineering seismic hazard and risk assessment of selected cities in the Balkan Region", CLSMEE-BAS - DST-UNIVTS, May-June 2000.

Paskaleva, I., Matova, M., Frangov, G. (2002), Expert assessment of the displacements provoked by seismic events: case study for the Sofia metropolitan area (Pageoph Topical Volumes, Birkhauser Verlag this isue)

PETKOV. I., A.SD CHRISTOSKOV, L. (1965), On seismicity in the region of the town of Sofia concerning the macroseismic zoning, Ann. Sofia Univ. 58, 163-179

PEIRON, P., ILIEV, I. (1970). The effect of engineering geological conditions on seismic microzoning in Sofia, Proc. $3^{\text {rd }}$ Eur. Symposium on EE, Sofia. 79-86.

Ralglelov, B. (1996), Seismicity and site effects on the Sofia valley district, Proc. $1^{\text {st }}$ WG meeting, Oct. 31 - Nov. 3 , Sofia, $28-31$

Raliglelov, B., Toteva. T. (1998), Recent seismicity observed around Sofia city, Proc. $3^{\text {rd }}$ WG meeting, Dec. 2-5, Sofia. 7-9.

ROMPLLS Earthquake catalogue, Romanian catalogue on line, computer file, www.infp.infp.ro.

SEED H.B.. A.ID IDRISS, I. M. (1982), Ground motions and soil liquefaction during earthquakes, EERI, I-134.

Shtiol, S.. SPASSOV, E., GEORGIEV, T. (1992), Evidence for the existence of a paleosubduction zone beneath the Rhodopean massif(Central Balkan), Tectonophysics 206, 307-314.

Shebald;, N., Leydecker, G., Mokrushina, N. TateVossian, R., Erteleva, O., Vassiliev, V., Earthquake Catalogue for Central and Southeastern Europe 342 BC - 1990 AD, (European Commission, Report No. ETNU CT 93 - 0087) (1999)

SLAVOV. SL.. Ground motion modelling in the City of Sofia (TRIL - ICTP Visitors report) (2000).

SOlakov, D., SIMEONOVA, St., ChRISTOSKOV, L. (2001), Seismic hazard assessment for the Sofia area, Annali di Geofisica 44. 3. 541-555.

STA.ishKOVA. I., and SLEJKO, D. (1991), Seismic hazard of the main Bulgarian cities, In Atti del $10^{\circ}$ Convegno Annuale del Gruppo Nazionale di geologica della terra solida; Roma. 6-8 Novembre, 1991, 123-134.

SLX, R., VACCARI, F., MARRARA, F., PANZA, G.F. (1998), The main features of the local geological conditions can explain the macroseismic intensity caused in Xiji-langfu (Beijing) by the MS=7.7 Tangshan 196 earthqt ake, Pageoph 152, 507-521.

TOdorovska,M., Paskaleva, I., Glavcheva, R. (1995), Earthquake source parameters for seismic hazard assessment: examples of Bulgaria, Proc.10th ECEE, Vienna, Austria.

Triavtafyllidis, P., Hatzidmitriou, P. M., SuHadolC, P., Theodulidis, N., and PITLAKIS, K. (1998), Comparison between I-D and 2-D site effects modelling, In The effests of the surface geology on seismic motion, (Ed. Irikura, K., Kudo, K., Okada H., and Sasatani , T.) (Balkema. Rotterdam, 2) pp. 981-986.

TZANKov, TZ., AND NIKolov G. (1996), Recent bilateral listric destruction in Western Stara Planina Mountain anci Western Fore Balkan, Bulgaria, C.R.Bulg. Acad. Sci. 49, 4, .53-55.

VACCARI, F., GREGERSEN, S., FLRLAN, M., PANZA, G.F. (1989), Synthetic seismograms in laterally heterogeneous, anelsatic media by modal summation of P-SV waves, Geoph.. J. Int. 99. 285-295.

VACCARI F., NLXZIATA C., FÄH, D., PANZA, G.F. (1995), Reduction of seismic vulnerability of megacities: the cases of Rome and Naples, Proc. $5^{\text {th }}$ int. conf. on Seismic Zonation, EERI, Oct., 1995, Nice, France, 1392-1399.

VIRIELX, J. (1984), SH - velocity-stress finite-difference method: velocity-siress finite-difference method, Geophysics 49. 1933-1957.

VIRIEUX. J. (1986), P-SV wave propagation in heterrogenoues media: velocity-stress finite-difference method, Geophysics $51,889-901$. 